\title{
ALGUNS ASPECTOS \\ DA HETEROGENEIDADE DIALETAL BRASILEIRA: CONSTRUÇÕES SINTÁTICAS A PARTIR DOS PRONOMES SUJEITO E OBJETO
}

\author{
Vicente Cerqueira (UFAC) \\ vicente.cerqueira@gmail.com \\ Marcelo Leal Lima (UFAC) \\ marceloleal16@gmail.com
}

Sem perceber, as pessoas vão se familiarizando com o emprego de formas linguísticas e muitas vezes não têm consciência da heterogeneidade dialetal que naturalmente praticam. Segundo Bagno: será impossível escrever uma única gramática que dê conta de todas as variedades linguísticas do português brasileiro, nem de seus incontáveis usos. Estudos comparativos mostram diferenças entre as variedades do português brasileiro e o prescritivo. Galves propõe que a norma padrão e a variedade brasileira têm gramáticas diferentes. Essas distinções estão bem visíveis no sistema flexional e pronominal, como apontam Galves, (1983/1988; 1998); Paggoto (1993), Nunes (1993) e Kato $(1999)^{28}$ entre outros. A divergência é explícita no caso dos pronomes sujeito e objeto. A norma padrão em acordo com a língua portuguesa de Portugal impõe um modelo pronominal, mas foi perpetuado outro, tratando-se do Brasil.

Galves (1983-1988) no que diz respeito ao sistema pronominal sujeito e objeto aponta vários aspectos que diferenciam a sintaxe pronominal do português do Brasil e a norma padrão. O padrão prescritivo da língua portuguesa aborda três pronomes sujeito para o singular e outros três para o plural. Esse paradigma pleno e histórico é o veiculado, e o que tentam transmitir. De acordo com Assis: o português brasileiro reduz esse sistema histórico. Nele há quatro pessoas flexionais distintas e não seis, como no padrão histórico e prescritivo. Esta assertiva é comprovada com exemplos de Mattos e Silva (2002):

\footnotetext{
${ }^{28}$ Não foram indicadas as obras desses autores nas "Referências Bibliográficas", assim como de diversos outros referidos no corpo do artigo.
} 
- eu lembro

- você, ele, a gente lembra

- nós lembramos

- vocês, eles lembram

Em alguns lugares do Brasil, convive com esse sistema, outro mais simplificado, conforme demonstra Rosa Maria de Assis (1982 e 1988). Nele estão, a forma que se refere à primeira pessoa, ou seja, o falante que leva o verbo para a forma flexional de $1^{\text {a }}$ pessoa e o que se refere aos outros, com o falante incluído ou não, sem a oposição de singular/ plural na flexão verbal, conforme os exemplos:

- eu alembro de todos

- a gente percisa d'uma escola

- nós pranta é mamona

- ele morava in Lontra

- eles tira o quarto ano

Os falantes do português popular corrente excluem os pronomes tu e vós (embora haja variantes regionais que selecionam o tu com o verbo na flexão histórica e outras que mantêm o tu com o verbo na terceira pessoa do singular). Com isso a flexão verbal fica drasticamente simplificada e a ela estão interligadas as regras de concordância verbo-nominal, exigidas na norma padrão. Naro, em seu artigo diz que a variação na concordância, tanto verbo-nominal como no interior do sintagma nominal, é o fato sintático mais transparente na sintaxe brasileira em relação ao português padrão.

F. Tarallo e Maria Eugênia Duarte (1988), em interessante artigo, demonstram como se processa a variação da expressão do objeto anafórico no português brasileiro corrente.

Retomando esses autores:

Uma resposta à questão:

(1) Há quanto tempo você conhece a Maria?

poderia desencadear uma das seguintes respostas: 
(1a) Eu conheço a Maria há muitos anos

(1b) Eu conheço ela há muitos anos

(1c) Eu conheço (e) há muitos anos

(1d) Eu a conheço há muitos anos

Sendo a resposta em (1d) "aquela que corresponde à estrutura cada vez menos frequente na fala." (1988, p. 49-50) Em usos correntes vemos essa construção sintática na linguagem popular.

A estrutura (1d) é aquela que a norma padrão cultiva, porém a menos utilizada pelos falantes. O uso dos pronomes oblíquos está cada vez mais restrito a manifestações extremamente monitoradas de língua falada. Os pronomes objeto de $3^{\mathrm{a}}$ pessoa estão, senão totalmente mortos. Conhecem esses pronomes (mas nem por isso usam) as pessoas que tiveram contato direta ou indiretamente com a normapadrão conservadora. A melhor prova é que eles não aparecem na fala nem das crianças que frequentam a escola ou dos adultos analfabetos ou semianalfabetos. Até mesmo na fala de brasileiros cultos o uso dos pronomes oblíquos átonos (também chamados de clíticos de $3^{\mathrm{a}}$ pessoa) é raríssima. O uso dos clíticos é considerado "certo demais", "polido" etc. Em seu estudo de 1989, Duarte registra que os falantes cultos, diante de enunciados construídos com os pronomes oblíquos, reagiram dizendo: "Pode estar certo, mas ninguém fala assim!";

O pronome lexical (1b) é favorecido por estruturas sintáticas complexas, com predicativo ou objeto sentencial, associado ao traço [+ animado] do objeto. O uso do pronome ela, por sua vez, é associado (sem razão) às variedades linguísticas de falantes com baixa escolaridade, por isso os falantes cultos evitam pronunciá-la (mas nem sempre conseguem). Na verdade há uma explicação linguística a respeito do uso de um pronome reto (isto é, sujeito) onde deveria aparecer um pronome oblíquo (isto é, objeto), eis uma estrutura de pronominalização muito utilizada por brasileiros, um pequeno exame da história da língua, desde suas raízes latinas, pode ajudar nesta questão. Na língua latina clássica não existiam pronomes-sujeitos e nem pronomes-objetos para a $3^{\text {a }}$ pessoa. Existia o ego (sujeito), de onde vem nosso eu e o me (objeto direto); existia o tu que herdamos para o sujeito, e o te (objeto direto). Havia também seus respectivos plurais: nos e vos. Para a $3^{\mathrm{a}}$ pessoa, não havia nada. Mesmo os pronomes $e$ go, $t u$, nos, vos eram pouco empregados, já que a desinência do ver- 
bo permitia a omissão do pronome-sujeito. Na formação do latim vulgar, do qual surgiram as línguas românicas, sentiu-se a necessidade de preencher os vazios do quadro dos pronomes pessoais no tocante à $3^{a}$ pessoa. Para esse preenchimento foram utilizados os pronomes demonstrativos ille, illa, illud (este último para o gênero neutro, que depois desapareceu), que originalmente equivaliam à aquele, aquela, aquilo. É fácil reconhecer em ille e illa os antepassados dos nossos ele e ela (lembramos que até meados do século XX esses pronomes eram escritos êlle e ella). Curiosamente, desses mesmos pronomes demonstrativos latinos saíram os artigos definidos e os pronomes oblíquos átonos de $3^{\mathrm{a}}$ pessoa do português $(o, a, o s, a s)$, depois de uma série de transformações fonéticas e morfológicas.

Na análise do linguista brasileiro Mattoso Câmara Jr. (1972), esses pronomes demonstrativos, mesmo depois de incorporados ao quadro dos pronomes pessoais do caso reto, não se integraram completamente em sua classe nova. Em toda essa história, os normativistas, quando querem justificar suas proibições e condenações, muitas vezes recorrem às origens da língua, porém no caso dessa retomada é inviável. Dessa forma, por que as pessoas não podem usar o pronome ela, tomando como exemplo a oração do artigo, se o pronome latino da qual ele origina podia exercer essa função sintática e quando a produzimos na fala ou na escrita somente a retomamos? Eis a questão de trabalhar essa explicação com falantes brasileiros, a respeito desse uso bastante comum.

A categoria vazia (objeto nulo) é a estratégia de pronominalização preferida. Uma prova da desatenção da tradição gramatical no que diz respeito às categorias vazias é que o objeto nulo não aparece em nenhuma gramática normativa nos capítulos dedicados aos pronomes oblíquos ou à análise sintática dos objetos, embora seja a estratégia mais amplamente empregada por falantes do português brasileiro. Em linguística, as chamadas categorias vazias são muito importantes para uma melhor compreensão do funcionamento da língua. Neste caso recebem a ampla preferência dos falantes cultos e não cultos, que usam esse recurso como economia linguística ou como um modo de evitar o "certo demais" e o suposto "errado demais". Essa preferência pelo pronome nulo se apoia, na capacidade que temos de interpretar adequadamente as categorias vazias da língua, com base nas estruturas sintáticas constitutivas da nossa gramá- 
tica e de interpretar, também, o contexto verbal e não verbal dos enunciados.

O clítico acusativo varia desde a completa ausência (nos jovens, até poucas ocorrências na fala de pessoas com nível de educação superior). O que indica uma mudança de perda desse elemento.

O pronome lexical tem bastante ocorrência na fala de pessoas em geral (foi explicitado o por que desse uso ser comum e sua explicação linguística do uso) e decresce conforme o aumento da faixa etária e escolaridade, e está condicionado à complexidade maior da estrutura em que o objeto aparece. Esta estratégia também é muito utilizada por brasileiros. Mais provável em exemplos do tipo:

- Eu acho ele simpático em vez de: Eu o acho simpático

- Eu gostaria de ter visto ele em vez de: Eu gostaria de tê-lo visto

- Eu vi ele sair de casa em vez de: Eu o vi sair

do que em frases do tipo: Eu vi ele ontem por $\mathrm{Eu}$ o vi ontem.

Entre os falantes de faixa etária e escolaridade alta, dizem, ainda, há preferência pelos sintagmas nominais lexicais (1a).

Chegam à conclusão de que os dados sugerem que a categoria vazia e o sintagma lexical são "importantes estratégias de esquiva" por um lado em relação ao uso do clítico, em processo de desaparecimento; por outro, em relação ao uso do pronome lexical, avaliado como estigmatizante (id. ibid., p. 52).

Aqui está um pequeno recorte da ampla realidade dialetal com alguns aspectos da sintaxe pronominal brasileira. A língua do Brasil sempre será diferente da norma padrão até por uma questão de realidades.

Muito se escreveu sobre a emergência de uma língua brasileira em oposição à tradicional língua portuguesa. Fortes e contundentes argumentos já foram erigidos em defesa de uma ou outra tendência, a saber: se a língua permanece unicamente lusitana ou se, ao contrário, já teria transpirado, há algum tempo, um certo ar de brasilidade. (TARALLO, 1993, p.69) 


\section{REFERÊNCIAS BIBLIOGRÁFICAS ${ }^{29}$}

CÂMARA JR. J. Mattoso. Erros escolares como sintomas de tendências linguísticas no português do Rio de Janeiro. In:

Dispersos. Edição de Carlos Eduardo Falcão Uchôa. Rio de Janeiro: Fundação Getúlio Vargas, 1972, p. 35-36.

LEMLE, M. Heterogeneidade dialetal: um apelo à pesquisa. Tempo Brasileiro", 53/54 (Linguística e Ensino do Vernáculo), p. 60-94, 1978.

MATOS E SILVA, Rosa Virgínia. Contradições no ensino de português: a língua que se fala $\mathrm{X}$ a língua que se ensina. 5. ed. São Paulo: Contexto, 2002.

NARO, A. J.; Scherre, M. Variação e mudança linguística: Fluxos e contrafluxos na comunidade de fala. Cadernos de Estudos Linguísticos, 20, p. 9-16, 1991.

POSSENTI, Sírio. Por que (não) ensinar gramática na escola. Campinas: Mercado de Letras, 1996.

TARALLO, F. (Org.). Fotografias sociolinguísticas... p. 300-332.

${ }^{29}$ Estas referências bibliográficas estão incompletas. 